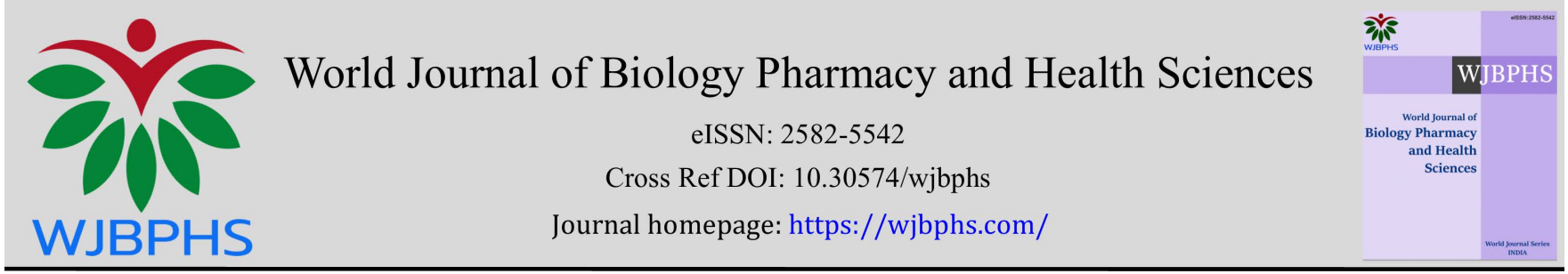

(REview ARTICLE)

\title{
Features of occupational stress in doctors and other medical practitioners
}

\author{
Victoria Fedorovna Jekova * \\ Department of Health Policy and Management, Faculty of Public Health, Medical University - Sofia, Bulgaria.
}

World Journal of Biology Pharmacy and Health Sciences, 2021, 06(03), 013-019

Publication history: Received on 21 April 2021; revised on 30 May 2021; accepted on 02 June 2021

Article DOI: https://doi.org/10.30574/wjbphs.2021.6.3.0059

\begin{abstract}
The high pace of modern life is a factor that creates psycho-emotional stress. Stress is an important mechanism for coping with every day's challenges. Problems start to occur when the stress response is inappropriate to the size of the challenge. If not managed, high stress levels result in high levels of dissatisfaction, mental and physical illness, burnout, decreased productivity, and as a result, difficulty in providing quality service to clients. Constant stress negatively affects not only the state of the nervous system, but also the body as a whole. People in some occupations are in contact with stressors almost constantly. This group includes medical professionals. The effect of occupational stress on doctors not only has potential negative consequences for their patients, but also represents a substantial potential cost to the public health sector in terms of impaired doctors' performance, together with the need for retraining and additional recruitment to offset wastage. This review analyses the topics of what stress is, what occupational stress is and what classifications exist for it, why occupational stress and burnout is common among physicians, and how it can be recognized and prevented.
\end{abstract}

Keywords: Stress; Doctors; Physical health; Mental health; Burnout

\section{Introduction}

The World Health Organization [WHO] European Conference (2005) notes that work-related stress is an important issue for about one third of workers in the European Union. The costs of dealing with mental health problems due to occupational stress are on average $3-4 \%$ of gross national income [1].

The health of the population is the most valuable resource and indicator of the welfare and prosperity of the country. According to the WHO constitution, health "... is a state of complete physical, mental and social well-being and not merely the absence of disease or infirmity"[2]. And while the general well-being and mental health of patients is the most important focus in the new era of a patient-centered approach, the psychological and social well-being of health professionals is often given much lower priority.

The relevance of this question is difficult to overestimate, as it is important not only for doctors themselves, but also for patients and the general population. Researchers are now paying increasing attention to the socio-psychological aspects of medical practice, but this area has not yet been fully explored. Identifying and analyzing existing problems will improve the quality of life of both healthcare practitioners and their patients.

\section{Research aim and methodology}

The aim of the present study is to investigate the stress mechanisms and features of stress in health care workers.

\footnotetext{
${ }^{*}$ Corresponding author: Victoria Jekova
}

Department of Health Policy and Management, Faculty of Public Health, Medical University - Sofia, Bulgaria. 
The following methods have been used in the survey:

- Documentary method - use of various documents, guides and reports in the field of stress theories, occupational stress and features of occupational stress in doctors.

- Comparative analysis - comparison of published guidelines and researches.

- Empirical method - comparison and putting together of data from different types of documents and sources.

- Historical analysis - monitoring of stress and copying theories over time.

\section{Results and Discussion}

\subsection{Stress as a Response, Stimulus and Transaction}

Stress as a response model was introduced by Hans Selye (1956) and describes stress as a physiological response pattern and was captured within his general adaptation syndrome (GAS) model [3]. This model describes stress includes three concepts [4].

- Stress is a defensive mechanism.

- $\quad$ Stress follows the three stages: I. alarm, II. Resistance and III. Exhaustion [Fig. 1].

- If the stress is prolonged or severe, it could result in diseases of adaptation or even death.

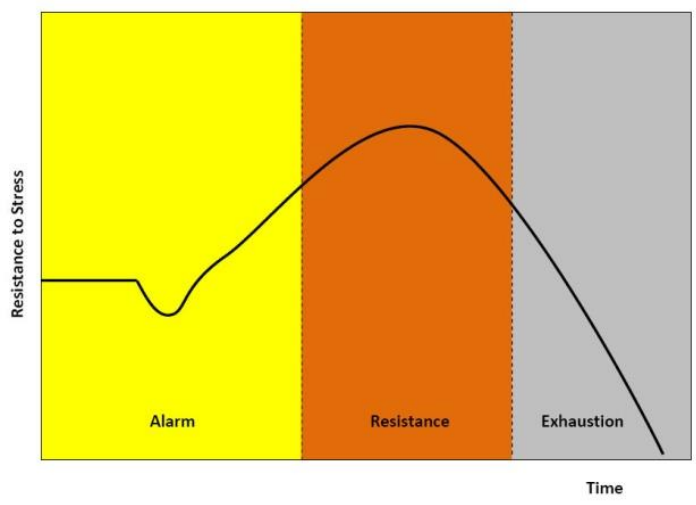

Figure 1 GAS model by Selye [3]

In 1983 in "The Stress Concept: Past, Present and Future", Selye [5] introduced the idea that the stress response could result in positive or negative outcomes. In this way, stress could be experienced as eustress (positive) or dystress (negative).

The theory of stress as a Stimulus viewed stress as a significant life event or change that demands response, adjustment, or adaptation. Holmes and Rahe in 1967 created the Social Readjustment Rating Scale (SRRS) consisting of 42 life events scored according to the estimated degree of adjustment they would each demand of the person experiencing them (e.g., death of parent, abortion, marriage, loss of job, divorce, relocation, loss of loved one)[6]. The stress as stimulus theory assumes:

- Change is inherently stressful.

- Life events demand the same levels of adjustment across the population.

- There is a common threshold of adjustment beyond which illness will appear.

In attempting to explain stress as more of a dynamic process, Richard Lazarus developed the transactional theory of stress and coping [7-9], which presents stress as a product of a transaction between a person (including multiple systems: cognitive, physiological, affective, psychological, neurological) and his or her complex environment. The main points of this theory are:

- Transaction (interaction) occurs between a person \& the environment.

- $\quad$ Stress results from an imbalance between (a) demands \& (b) resources. 
- Thus we become stressed when demands (pressure) exceeds our resources (our ability to cope \& mediate stress).

- Thus the interpretation of the stressful event was more important than the event itself [10].

- The nature of stress was described in multiple ways: acute, episodic or intermittent, and chronic. Different types of stressors emerged, such as event, situation, cue, and condition, which then fell into categories based on locus of control, predictability, tone, impact, and duration [11].

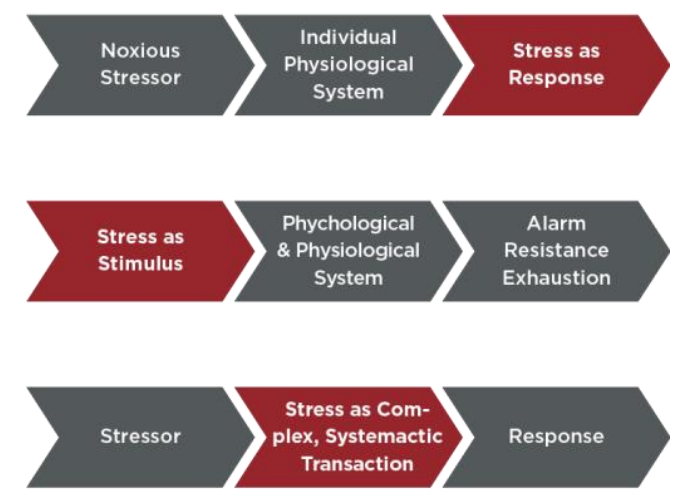

Figure 2 Stress as response, stimulus and transaction $[12,13]$

\subsection{Occupational Stress}

Occupational stress is a diverse phenomenon, which is expressed in mental and somatic reactions to stressful situations in a person's work. Stress can be caused by both individual characteristics of the person and the characteristics of his professional activity and work environment. More often, knowledge workers are exposed to occupational stress [14].

The reason for the development of professional stress can be not only too large a set of professional responsibilities, but also insufficiently clear requirements from management, long way to work, difficult relationships with colleagues, low salaries, lack of prospects for development and even insufficient workload.

Workplace stress can be caused not only by psychological aspects, but also by working conditions that do not meet sanitary standards: insufficient lighting, low or high room temperature, lack of adequate air exchange. When working in such conditions, the body works at the limit of its adaptive resources, which leads to depletion.

Psychologists from the University of Manchester have studied the influence of stressors on workers in various occupations [15]. According to this study, miners, police officers, doctors, journalists, pilots, actors, politicians and the public are at greatest risk of burnout.

There is no single classification of occupational stress.

N.V. Samukina identifies the following types of stress $[16,17]$ :

- competition stress;

- fear of making a mistake;

- professional achievement stress;

- Discrepancy in the pace of communication between employees.

Western literature identifies six main sources of occupational stress [18]:

\subsubsection{Operating mode}

This includes over-intensive work, lack of free time and rest, poor working conditions.

\subsubsection{Communication}

Lack of understanding with bosses, colleagues, lack of respect from subordinates. 


\subsubsection{Role factor}

High responsibility, small powers, undefined role of the employee in the organization.

\subsubsection{Career difficulties}

Absence or too fast career growth, fear of dismissal, mismatch of the employee's professional ambitions with his abilities.

\subsubsection{Psychological climate in the workplace}

Contradictions between corporate culture and internal beliefs of an employee, intrigues between employees, restriction of freedom of choice.

\subsubsection{Extra-organizational factors}

Family conflicts, lack of mutual understanding on the part of relatives.

Globally, all causes of occupational stress can be divided into subjective and objective [19]. The first group of reasons is due to the psychological characteristics of a person, his perception of the reality around him. It is more difficult to influence objective reasons because they affect all employees of a particular organization. These include hazardous working conditions (dust, noise, radiation, high or low temperatures, constant danger to life and health), intensive work schedule and increased responsibilities.

Depending on the type of factors there are [19]:

- Information stress caused by severe mental and physical overload. This mode of operation affects its quality, over time it causes chronic fatigue, inability to make decisions and perform even relatively simple work.

- Emotional stress is typical of people who do not know how to adapt to existing circumstances and who are constantly opposed to the team.

- Communicative stress is related to the lack of ability to establish a healthy working relationship, to resist the aggression directed at him (by the team).

\subsection{Peculiarities of occupational stress in healthcare practitioners}

Doctors are exposed to high occupational stress and risk of burnout. In the work of doctors of different specialties there are always such factors as constant communication with a large number of people, intensive work schedule and great responsibility for every decision made. Healthcare workers are often forced to work night shifts, disrupting normal biorhythms and disrupting the sleep-wake cycle. In addition, doctors see the suffering and death of other people every day, bosses often have higher demands on them, and working conditions and pay do not match the level of responsibility that every doctor has.

Occupational burnout in doctors is characterized by the following manifestations: feeling tired, exhausted; headache; fluctuations in blood pressure; sleep disorders; negative attitude towards work; irritability; anxiety; negative attitude towards oneself; wines; reduced memory; low labour productivity; cynicism; feeling of incompetence.

Exposure to occupational stress depends on individual physiological characteristics and personality type [20]. Several categories of health workers are most prone to burns. Conscientious, orderly, people striving for order are very worried about any failure. The deterioration of the condition and even more the death of the patient cause them a deep sense of guilt, even if they did everything right. This provokes constant inner experiences, which ultimately lead to severe psychosomatic disorders.

Doctors who always strive to be the best react painfully to criticism. In addition, they cannot perform monotonous work for a long time. Activities in such conditions quickly lead to burns.

People who are impressionable and empathetic also fall victim to occupational stress. Perceiving another's pain as their own, they quickly destroy their own psyche.

There are three phases of occupational stress in physicians [14]: 


\subsubsection{Voltage phase}

Sharp feelings, self-dissatisfaction, anxiety prevail.

\subsubsection{Resistance phase}

There is a decrease in emotional energy, the person tries to reduce the list of his functional duties. In the family and when communicating with friends, the doctor also becomes less emotional.

\subsubsection{Exhaustion phase}

Deficiency of emotions, rudeness, aggression, lack of empathy, resentment, withdrawal, psychosomatic and autonomic

\subsection{Recognizing and dealing with stress among healthcare workers}

Steps for recognizing and dealing with stress were described in 2012 by Prof. Zaharina Savova, Bulgaria [21]:

- It is very important how a person perceives the stressor - incorrectly or realistically;

- The following is an assessment of the situation in terms of severity and importance, how threatening it is and in what way. Past experience determines the point of view, the assessment of events and ourselves, as well as the belief in the ability to deal with certain situations.

- The next step is to choose the right solution to counteract the stressor-action solution. Here the individual and psychological features of the individual such as temperament, level of anxiety, type of thinking, and orientation of the character have a strong influence. When the solution of the problem situation is centered on the problem, the strategy aims to influence and direct the interaction between the individual and the environment. The individual makes an analysis of the situation, prepares a plan, seeks help from others, and seeks additional information. Strategies of this type are called active and are preferred in situations judged by the subject to be favorable for positive change;

- An emotion-centered strategy implies an impact on oneself. This strategy is called passive and is characterized by distancing, avoiding, escaping; its purpose is to maintain the emotional balance of the individual. This form of reaction is characterized by naivety and infantile assessment of the situation and experience.

Stress reduction interventions among healthcare workers are categorized as either organizational-directed interventions or individual-focused interventions. Listed below is a synthesis of mostly used and scientifically studied general stress management techniques [22-29]:

Table 1 Stress management techniques

\begin{tabular}{|l|l|l|l|}
\hline Cognitive & Physical & Environmental & Other \\
\hline Therapy & Yoga & Music & Conflict Resolution \\
\hline Hobbies & Deep Breathing Techniques & Nature & Prayer \\
\hline Meditation & Relaxation & Pets & \\
\hline Mindfulness & Physical Exercize & Spa Therapy & \\
\hline Planning & Plant Medicine & & \\
\hline Reading & Art Therapy & & \\
\hline Time Management & Massages & & \\
\hline
\end{tabular}

\section{Conclusion}

Unfortunately, most medical institutions do not pay the necessary attention to the prevention of occupational burnout. That is why there are so many complaints from healthcare professionals about patients. The constant is also the reason why many health professionals change their field of activity. 
Abroad, special trainings are held for doctors, allowing doctors to express their emotions, find understanding and support, resolve internal conflicts and relieve tension. In some countries, the prevention of burnout is enshrined in law. It is important to develop and implement programs for psychological rehabilitation of medical staff.

Occupational stress has a negative impact on the quality of health care delivery and the lives of health professionals. That is why this problem must be given due attention. The profession of doctor and nurse is associated with daily stress, which is why the group and individual work of psychologists with health professionals is an important aspect of the prevention of psychosomatic disorders. Constant mental stress in the workplace not only leads to behavioral disorders, but also causes serious disorders of the nervous and cardiovascular systems. The best way to deal with the adverse consequences is to prevent constant stress, to create conditions for psychological relief of health workers.

\section{Compliance with ethical standards}

\section{Acknowledgments}

Author expresses special thanks of gratitude to Prof. Zaharina Savova, PhD, for the inspiration on the subject and to Prof. Dr. Tzekomir Vodenicharov, Sc. D, for overall support and motivational example.

Disclosure of conflict of interest

The authors declare no competing interests.

\section{References}

[1] https://apps.who.int/iris/bitstream/handle/10665/43337/9241546794_eng.pdf

[2] https://www.who.int/about/who-we-are/constitution

[3] Sage Lazarus RS, Folkman S. Psychological Stress and the Coping Process. New York, NY: Springer; 1984.

[4] Selye H. Stress in Health and Disease. Reading, MA: Butterworth; 1976.

[5] Selye H. The Stress Concept Past, Present and Future. New York, NY: John Wiley \& Sons; 1983.

[6] Holmes TH, Rahe RH. The Social Readjustment Rating Scale. J Psychosom 1997; 11(2): 213-8.

[7] Lazarus RS. Emotion and adaptation. New York, NY: Oxford University Press; 1991.

[8] Lazarus RS. Evolution of a Model of Stress, Coping, and Discrete Emotions. In V. H. Rice (Ed.). 2000.

[9] Lazarus RS. Psychological Stress and the Coping Process. New York, NY: McGraw-Hill; 1966.

[10] Sage Lazarus RS, Folkman S. Psychological Stress and the Coping Process. New York, NY: Springer; 1984.

[11] Stangor C, Walinga J. Introduction to Psychology - 1st Canadian Edition. Victoria, B.C.: BC campus; 2014.

[12] https://opentextbc.ca

[13] https://positivepsychology.com

[14] Kitaev-Smik, L, Psychology of Stress - Moscow: Education. 1983.

[15] Leonova A, Chernisheva O. Psychology of Working and Organizational Psychology. Chitatel-M: Education; 1995.

[16] Shcerbatih Y. Psychology of Stress and Correction Methods. SPb; 2007.

[17] Samukina N.V. Nervoznost ili stress v jizni [Irritability or stress in life]. Kariera 2005; 12: 40-45.

[18] Stangor C, Walinga J. Introduction to Psychology - 1st Canadian Edition. Victoria, B.C.: BC campus; 2014.

[19] Chereshnev V, et al. Experimantal models in pathology. Perm: Press; 2011.

[20] Vinokur V. Occupational stress in medical practitioners. Vestnik МАПО;. 2002: 2; 4.

[21] Savova Z. Prevention of Stress and Burnout. Sofia: Simolini 94; 2012. 
[22] Duchemin A.-M. et al. A small randomized pilot study of a workplace mindfulness-based intervention for surgical intensive care unit personnel: Effects on salivary $\alpha$-Amylase levels. Journal of Occupational and Environmental Medicine, 2015; 57:393-399.

[23] Sims J. The evaluation of stress management strategies in general practice: an evidence-led approach. British Journal of General Practice, 1997; 47:577-582.

[24] Kjeldmand D., Holmstrom I. Balint groups as a means to increase job satisfaction and prevent burnout among general practitioners. The Annals of Family Medicine, 2008; 6:138-145.

[25] Brooks D. et al. Creative approaches for reducing burnout in medical personnel. The Arts in Psychotherapy, 2010; 8:255-263.

[26] West CP, Dyrbye LN, Erwin PJ, Shanafelt TD. Interventions to prevent and reduce physician burnout: a systematic review and meta-analysis. The Lancet, 2016; 388 10057:2272-2281.

[27] Burton A, Burgess C, Dean S, Koutsopoulou GZ, Hugh-Jones S. How Effective are Mindfulness-Based Interventions for Reducing Stress Among Healthcare Professionals? A Systematic Review and Meta-Analysis. Stress Health 2017; 33 1:3-13.

[28] Stratton E, Lampit A, Choi I, Calvo RA, Harvey SB, Glozier N. Effectiveness of eHealth interventions for reducing mental health conditions in employees: A systematic review and meta-analysis. PLoS One, 2017; 12: 12:e0189904.

[29] Xu, Hui (Grace); Kynoch, Kathryn; Tuckett, Anthony; Eley, Robert ${ }^{3}$; Newcombe, Peter Effectiveness of interventions to reduce occupational stress among emergency department staff: a systematic review protocol, JBI Database of Systematic Reviews and Implementation Reports, 2019; 17(4): 513-519. Available from doi: 10.11124/JBISRIR-2017-003955 